\title{
Analisis Kemampuan Pemecahan Masalah Matematis : Dampak Blended Learning Menggunakan Edmodo
}

\author{
Fifit Novi Yanti $^{1}{ }^{*}$, Farida ${ }^{1}$, Iip Sugiharta ${ }^{1}$ \\ 1Universitas Islam Negeri Raden Intan Lampung. Jalan Endro Suratmin, Sukarame, Bandar \\ Lampung 35133, Indonesia. \\ *Corresponding Author. E-mail: fifitnoviyanti181195@gmail.com
}

\begin{abstract}
Abstrak
Penelitian ini di latarbelakangi oleh rendahnya kemampuan pemecahan masalah matematis dikarenakan pembelajaran yang kurang efektif terutama kurangnya jam pelajaran. Blended learning merupakan model pembelajaran dua arah yaitu pembelajaran tatap muka dan online, sedangkan E-learning merupakan model pembelajaran tanpa tatap muka. Model pembelajaran blended learning dan e-learning membutuhakan media online seperti Edmodo. Upaya menyikapi permasalahan tersebut, peneliti bertujuan untuk mengetahui pengaruh kedua pembelajaran tersebut terhadap peningkatan kemampuan pemecahan masalah matematis. Metode penelitian yang digunakan pada penelitian ini menggunakan metode eksprimen semu ( Quasy eksprimental design) dengan jenis penelitian yang digunakan adalah pretest-postest control group design. Teknik pengumpulan data menggunakan teknik acak kelas, dimana populasi nya seluruh peserta didik kelas VIII SMP N 21 Bandar Lampung. Uji hipotesis yang digunakan adalah uji-gain dengan teknik analisa menggunakan one way anova. Dari hasil peneitian, pembelajaran blended learning dan e-learning menggunakan edmodo terdapat peningkatan kemampuan pemecahan masalah matematis dengan taraf klasifikasi sedang.
\end{abstract}

Kata kunci: Blended Learning, Edmodo, E-learning, Pemecahan Masalah Matematis

\section{Abstract}

This research is based on the background of the low mathematical problem solving abilities due to less effective learning, especially lack of lesson hours. Blended learning is a two-way learning model namely face-to-face learning and online learning, while E-learning is a face-to-face learning model. The blended learning and e-learning learning model requires online media such as Edmodo. Efforts to address these problems, researchers aim to determine the effect of these two learning on improving mathematical problem solving abilities. The research method used in this study uses quasi-experimental methods (Quasy experimental design) with the type of research used is the pretest-posttest control group design. The data collection technique uses a randomized class technique, where the population is all eighth grade students of SMP N 21 Bandar Lampung. The hypothesis test used is gain-test with analysis techniques using one way ANOVA. From the results of the study, blended learning and e-learning using edmodo there was an increase in mathematical problem solving skills with moderate levels of calcification.

Keywords: Blended Learning, Edmodo, E-learning, Mathematical Problem Solving

\section{PENDAHULUAN}

Rendahnya kemampuan pemecahan masalah matematis dikarenakan pembelajaran yang kurang efektif terutama kurangnya jam pelajaran. Untuk mengatasi permasalahan tersebut perlu adanya pembelajaran inovasi terbaru.
Sesuai dengan perkembangan zaman maka dalam proses pembelajaran telah banyak dikembang dengan mengoptimalkan pembelajaran seperti $e$ learning, sehingga e-learning sangat berkembang pesat (Monica, 2013). Pembelajaran e-learning merupakan teknologi pembelajaran yang berperan penting untuk siswa mengakses 
Desimal, 2 (2), 2019 - 174

Fifit Novi Yanti , Farida , Iip Sugiharta

pembelajaran jarak jauh (Nortvig, 2014). E-learning juga dijadikan sumber informasi online yang sangat berguna karena pembelajaran e-learning tidak harus melakukan tatap muka (Lane, 2016). E-learning digunakan sebagai pembelajaran mandiri bagi siswa (Hong, Giang, Phuong, \& Khanh, 2018). Pembelajaran e-learning sangat mudah untuk digunakan (Gloria \& Oluwadara, 2015).

Tidak hanya e-learning saja yang dapat meningkatkan kemampuan pemecahan masalah matematis namun blended learning juga dapat meningkatkan kemampuan pemecahan masalah matematis. Seperti yang dikatan (Manggabarani, Sugiarti, \& Masri, 2016) Blended Learning adalah suatu pembelajaran yang memadukan antara pembelajaran langsung (face to face) dan pembelajaran online. model pembelajaran Blended Learning mampu menciptakan proses pembelajaran berpusat pada peserta didik (Vernadakis, Giannousi, Derri, Michalopoulos, \& Kioumourtzoglou, 2012). Selain itu juga blended learning merupakan pembelajaran yang fleksibel dan penggunaan pembelajaran onlinenya merupakan salah satu bentuk contoh pembelajaran yang fleksibel dalam metode blended learning (Syarif, 2012). Blended Learning juga mampu meningkatkan interaksi antara pendidik dan peserta didik (Jusoff \& Khodabandelou, 2009).

Sejalan dengan penelitian yang dilakukan oleh (Ningsih \& Jayanti, 2016) dapat meningkatkan hasil belajar matematika. Blended learning merupakan model pembelajaran yang dapat meningkatkan daya tarik pada proses pembelajaran tatap muka (face-to-face) dan sangat sesuai untuk diterapkan di era 21. Hasil belajar siswa setelah menerapkan Blended Learning pada Mata Pelajaran Ilmu Bangunan di SMK Negeri 7 Surabaya mengalami peningkatan
(Rizkiyah, 2015). Model pembelajaran blended learning dapat meningkatkan kemandirian belajar

peserta didik (Sutisna, 2016). Penggunaan e-learning berbasis edmodo efektif untuk meningkatkan hasil belajar IPA pada siswa kelas VIII di SMP Negeri 2 Singaraja (Apriyana, Wirya, \& Parmiti, 2015). Sedangkan blended learning menggunakan Edmodo dapat meningkatkan hasil belajar peserta didik

Berdasarkan penelitian terdahulu, pengaruh blended learning terhadap hasil belajar (Ningsih \& Jayanti, 2016; Novitayati, 2013; Rizkiyah, 2015), dan motivasi belajar (Khoiroh, Munoto, \& Anifah, 2017; Kholifah \& Buditjahjanto, 2016; Manggabarani et al., 2016; Syarif, 2012) serta meningkatkan kemandirian siswa (Sari, 2013) dalam proses pembelajaran. Penelitian berikutnya pengaruh penggunaan media belajar elearning berbasis edmodo telah dilakukan oleh beberapa peneliti, seperti (Rahmaningrum \& Buditjahjanto, 2016; Sudibjo \& Wasis, 2013; Tigowati, Efendi, \& Budiyanto, 2017; Wijaya \& Arsyah, 2015) serta penelitian dalam meningkatkan kemampuan pemecahan masalah saat ini sedang banyak di teliti oleh pendidik (Amir, 2015; Dwi, Arif, \& Sentot, 2013; Hakim, 2014; Imam, Ayubi, \& Bernard, 2018; Muchlis, 2012; Muslim, 2015; Noviyana \& Fitriani, 2018; Setiawan \& Harta, 2014; Syazali, 2015; Wulandari, Mujib, \& Putra, 2016; Yuhani, Zanthy, \& Hendriana, 2018). Namun, saat ini belum ada penelitian yang meneliti tentang blended learning dan e-learning menggunakan edmodo. Maka, tujuan penelitian ini adalah untuk mengetahui apakah terdapat peningkatan kemampuan pemecahan masalah matematis dalam pembelajaran blended learning dan e-learning menggunakan edmodo?

\section{METODE}


Metode penelitian yang digunakan pada penelitian ini menggunakan metode eksprimen semu (Quasy eksprimental design) (Sugiyono, 2017). Variabel yang digunakan dalam penelitian ini terdiri dari variabel $\mathrm{x}$ dan $\mathrm{y}$ dimana variabel $\mathrm{x}$ nya adalah blended learning menggunakan Edmodo dan e-learning menggunakan Edmodo. Sedangkan variabel y nya adalah pemecahan masalah matematis. prestest-posttest control group design merupakan design penelitian yang digunakan (Sudijono, 2008). Teknik pengumpulan data menggunakan teknik acak kelas (Sugiyono, 2017) dimana populasi nya seluruh peserta didik kelas VIII SMP N 21 Bandar Lampung. Sampel penelitian yang digunakan adalah sebanyak 90 peserta didik yang terdiri dari kelas VIII A 30 peserta didik, VIII B sebanyak 30 peserta didik dan VIII C sebanyak 30 peserta didik. Kelas VIII A sebagai kelas e-learning dan VIII B sebagai kelas flipped classroom, sedangkan kelas VIII C digunakan sebagai kelas kontrol dimana kelas kontrol merupakan pembelajaran yang menggunakan metode ceramah. Uji hipotesis yang digunakan adalah uji- gain dengan teknik analisa menggunakan one way anova.

\section{HASIL DAN PEMBAHASAN}

Sesuai dengan rancangan penelitian yang digunakan bahwa penelitian ini menggunakan n-gain dengan teknik analisa anova satu jalur. Uji n-gain dilakukan setelah memenuhi syarat yaitu apabila data berdistribusi normal dan berasal dari varians yang sama. Sebelum dilakukannya uji normalitas dan uji homogenitas, dilakukannya uji descriptive guna untuk mengetahui nilai mean , median serta Std. Deviation. Dapat dilihat pada Tabel 1,2 dan 3.

Tabel 1. Uji Deskriptive Kelas Eksprimen dan Kontrol

\begin{tabular}{lccccc}
\hline \multicolumn{1}{c}{ Kelas } & Mean & Median & Maximum & Minimum & Std. Deviation \\
Blended Learning & 45.96 & 45.00 & 67.00 & 27.00 & 9.178 \\
E-learning & 43.00 & 43.00 & 57.00 & 30.00 & 7.856 \\
Kontrol & 41.56 & 40.00 & 57.00 & 27.00 & 8.084 \\
\hline
\end{tabular}

Tabel 2. Deskripsi Data Hasil Posttest Kemampuan Pemecahan Masalah Matematis

\begin{tabular}{lccccc}
\hline \multicolumn{1}{c}{ Kelas } & Mean & Median & Maximum & Minimum & Std. Deviation \\
Blended Learning & 75.60 & 75.00 & 100 & 57.00 & 9.72 \\
E-learning & 72.66 & 73.00 & 100 & 60.00 & 8.96 \\
Kontrol & 64.73 & 63.00 & 97.00 & 50.00 & 8.99 \\
\hline
\end{tabular}

Tabel 3. Deskripsi Data Hasil N-gain Kemampuan Pemecahan Masalah Matematis

\begin{tabular}{lccccc}
\hline \multicolumn{1}{c}{ Kelas } & Mean & Median & Maximum & Minimum & Std. Deviation \\
Blended Learning & 0.541 & 0.540 & 1.00 & 0.09 & 0.187 \\
E-learning & 0.509 & 0.481 & 1.00 & 0.07 & 0.185 \\
Kontrol & 0.38 & 0.374 & 0.95 & 0.11 & 0.16 \\
\hline
\end{tabular}

telah dilakukannya uji deskriptive, maka selanjutnya adalah menghitung uji normalitas dan homogenitas. Uji normalitas n-gain dapat dilihat pada Tabel 4 di bawah. Berdasarkan Tabel 4 bahwa bahwa kelas eksprimen dan kelas kontrol berdistribusi normal karena nilai sig $>\alpha$, dapat dilihat di tabel kolmogorvsmirnov. 
Desimal, 2 (2), 2019 - 176

Fifit Novi Yanti , Farida , Iip Sugiharta

Tabel 4. Hasil Uji Normalitas N-Gain Kelas Eksperimen dan Kelas Kontrol

\begin{tabular}{|c|c|c|c|c|c|c|c|}
\hline \multicolumn{8}{|c|}{ Tests of Normality } \\
\hline & \multirow{2}{*}{ VAR00002 } & \multicolumn{3}{|c|}{ Kolmogorov-Smirnova } & \multicolumn{3}{|c|}{ Shapiro-Wilk } \\
\hline & & Statistic & Df & Sig. & Statistic & df & Sig. \\
\hline \multirow[t]{3}{*}{ VAR00001 } & N-gain eks 1 & 0.124 & 30 & 0.200 & 0.946 & 30 & 0.130 \\
\hline & N-gain eks 2 & 0.096 & 30 & $0.20^{*}$ & 0.977 & 30 & 0.753 \\
\hline & $\mathrm{N}$-gain kontrol & 0.155 & 30 & 0.063 & 0.909 & 30 & 0.014 \\
\hline
\end{tabular}

a. Lilliefors Significance Correction

*. This is a lower bound of the true significance.

Setelah dilakukan uji normalitas maka dilakukan uji homogenitas, dimana uji homogenitas digunakan untuk mengetahui apakah data berasal dari varains yang sama atau tidak. Berdasarkan Tabel 5 bahwa data yang berasal dari varians yang sama karena nilai sig $>\alpha$. Dengan nilai sig 0.645

Tabel 5. Test of Homogeneity of Variance

\begin{tabular}{llcccc}
\hline \multirow{2}{*}{ VAR00001 } & $\begin{array}{c}\text { Levene } \\
\text { Statistic }\end{array}$ & df1 & df2 & Sig. \\
& Based on Mean & 0.441 & 2 & 87 & 0.645 \\
& Based on Median & 0.432 & 2 & 87 & 0.650 \\
& Based on Median and with & 0.432 & 2 & 86.709 & 0.650 \\
& adjusted df & & & & \\
& Based on trimmed mean & 0.474 & 2 & 87 & 0.624 \\
\hline
\end{tabular}

Setelah dilakukan uji homogenitas, maka selanjutnya dilakukan uji hipotesis untuk mengetahui apakah terdapat peningkatan yang siginfikan atau tidak. Berdasarkan Tabel 6 di bawah bahwa nilai sig $<\alpha$, sehingga dapat disimpulkan bahwa $\mathrm{H}_{0}$ ditolak. Dapat disimpulkan terjadi peningkatan yang signifikan antara kelas blended learning dan $e$ learning, sehingga pembelajaran blended learning dan e-learning lebih baik dari pada model pembelajaran konvensional.

Table 6. ANOVA

\begin{tabular}{lrrrrr}
\hline VAR00001 & \multicolumn{1}{c}{ Sum of Squares } & df & Mean Square & F & Sig. \\
Between Groups & 0.386 & 2 & 0.193 & 5.977 & 0.004 \\
Within Groups & 2.808 & 87 & 0.032 & & \\
Total & 3.194 & 89 & & & \\
\hline
\end{tabular}

Setelah dilakukan uji hipotesis maka dilakukan uji lanjut, dimana uji lanjut digunakan untuk mengetahui apakah terdapat perbedaan antara kelas eksprimen dan kelas kontol. Berdasarkan Tabel 7 bahwa tidak terdapat perbedaan antara blended learning dan e-learning dengan nilai signifikan sebesar 0.87 Karena pada dasarnya antara blended learning dan e-learning merupakan model pembelajaran yang mengunakan teknologi, dimana e-learning merupakan pembelajaran jarak jauh yang dapat digunakan pendidik dan peserta didik berinteraksi kapan saja dan dimana saja serta adanya timbal balik antara pendidik dan peserta didik. Sedangkan untuk blended learning dan e-learning ke kelas control apat terjadinya perbedaan karena kelas kelas kontrol masih menggunakan model pembelajaran konvenisonal yaitu model pembelajaran yang telah dilakukan 
Desimal, 2 (2), 2019 - 177

Fifit Novi Yanti , Farida , Iip Sugiharta

secara turun temurun seperti metode sekolah. ceramah yang banyak diterapkan di

Tabel 7. Uji Lanjut

\begin{tabular}{lcl}
\hline \multicolumn{1}{c}{ Kelompok } & Sig. & \multicolumn{1}{c}{ Keterangan } \\
Eksperimen 1 dan Eksperimen 2 & 0.87 & Tidak terdapat perbedaan \\
Eksperimen 1 dan Kontrol & 0.007 & Terdapat perbedaan \\
Eksperimen 2 dan Kontrol & 0.007 & Terdapat perbedaan \\
\hline
\end{tabular}

Berdasarkan perhitungan di atas terdapat peningkatan kemampuan pemecahan masalah matematis dengan taraf klasifikasi sedang. Namun dilakukan juga oleh (Syarif, 2012) bahwa terdapat peningkatan terhadap motivasi belajar peserta didik menggunakan blended learning. Penelitianyang dilakukan oleh (Rizkiyah, 2015) terdapat peningkatan hasil belajar peserta didik setelah diterapkannya model pembelajaran blended learning. (Jusoff \& Khodabandelou, 2009) terdapat peningkatan interaksi antara pendidik dan peserta didik. Namun berbeda dengan (Hadi, Fida Rahmantika Hadi, Rulviana, 2018) bahwa e-learning menggunakan Edmodo dapat meciptakan kenyamanan antara peserta didik dan pendidik.

Terdapat peningkatan kemampuan pemecahan masalah matematis peserta didik setelah diterapkannya model pembelajaran e-learning dan blended learning. Sejalan dengan penelitian yang dilakukan oleh (Syaiful, Kusumah, Sabandar, \& Dahrim, 2011) bahwa terdapat peningkatan kemampuan pemecahan masalah setelah diterapkannya model pembelajaran PMR. Kemampuan pemecahan masalah matematis menggunakan e-learning dan blended learning berada pada taraf klasifikasi n-gain sedang.

\section{SIMPULAN DAN SARAN}

Terdapat peningkatan kemampuan pemecahan masalah matematis menggunakan model pembelajaran blended learning dan e-learning, serta model pembelajaran blended learning dan e-learning dapat membantu peserta didik memecahkan suatu permasalahan yang ada pada soal pembelajaran.

Saran yang dapat peneliti berikan adalah dengan adanya blended learning dan e-learning dalam lingkup pembelajaran akan memudahkan peserta didik untuk berintraksi dengan guru. Pembelajaran blended learning dan $e$ learning harus lebih dikembangkan lagi khususnya untuk penggunaan edmodo agar melibatkan orang tua dalam penggunaannya, penggunaan aplikasi edmodo dalam lingkup pendidikan lebih di perdalam lagi khususnya untuk pendidik.

\section{DAFTAR PUSTAKA}

Amir, M. F. (2015). Pengaruh Pembelajaran Kontekstual terhadap Kemampuan Pemecahan Masalah Matematika Siswa Sekolah Dasar. In Prosiding Seminar Nasional Pendidikan: Tema "Peningkatan Kualitas Peserta Didik Melalui Implementasi (Pp. 34-42).

Apriyana, K. F., Wirya, N., \& Parmiti, D. P. (2015). Pengembangan Portal ELearning Berbasis Schoology Pada Mata Pelajaran IPS Kelas VIII di SMPN 1 Banjarangkan. E-Journal Edutech Universitas Pendidikan Ganesha, 3(1).

Dwi, I. M., Arif, H., \& Sentot, K. (2013). Pengaruh Strategi Problem Based 
Desimal, 2 (2), 2019 - 178

Fifit Novi Yanti , Farida , Iip Sugiharta

Learning Berbasis ICT terhadap Pemahaman Konsep dan Kemampuan Pemecahan Masalah Fisika. Jurnal Pendidikan Fisika Indonesia, 9(5), 8-17.

Gloria, A., \& Oluwadara, A. (2015). PreService Teachers' Ease of Use And Intention To Use Selected ELearning Technologies in Designing Instruction. American Journal of Educational Research, 3(10), 13201323.

Hadi, Fida Rahmantika Hadi, Rulviana, V. (2018). Analisis Proses Pembelajaran E-Learning Berbasis Edmodo pada Mata Kuliah Geometri. Jurnal Bidang Pendidikan Dasar (JBPD), 2(1).

Hakim, A. R. (2014). Pengaruh Model Pembelajaran Generatif terhadap Kemampuan Pemecahan Masalah Matematika. Jurnal Formatif, 4(3), 196-207.

Hong, N. T. T., Giang, T. T., Phuong, N. N., \& Khanh, M. Q. (2018). The Status of Applying E-Learning in Holding Students' Self-Study of the Subject Education in Pedagogical Universities In Vietnam. American Journal of Educational Research, 6(6), 804-810.

Imam, I., Ayubi, A., \& Bernard, M. (2018). Pengaruh Pembelajaran Berbasis Masalah terhadap Kemampuan Pemecahan Masalah Matematis Siswa SMA. Jurnal Pembelajaran Matematika Inovatif, 1(3), 355-360.

Jusoff, K., \& Khodabandelou, K. (2009). Reliminery Study on The Role of Social Presence in Blended Learning Environment in Higher Education. (Versi Elektronik). Journal of International Education Studies, 2(4), 82.
Khoiroh, N., Munoto, \& Anifah, L. (2017). Pengaruh Model Pembelajaran Blended Learning dan Motivasi Belajar Terhadap Hasil Belajar Siswa. Jurnal Penelitian Ilmu Pendidikan, 10(2), 97-110.

Kholifah, S. N., \& Buditjahjanto, I. G. P. A. (2016). Pengaruh Model Pembelajaran Blended Learning terhadap Hasil Belajar dan Motivasi Belajar Siswa Kelas XI TEI pada Mata Pelajaran Komunikasi Data dan Interface di SMK Negeri 1 Jetis Mojokerto. Jurnal Pendidikan Teknik Elektro, 5(3), 975-982.

Lane, S. (2016). Effective Online Discussion Forums As a Legal Learning Space. American Journal of Educational Research, 4(5), 392396.

Manggabarani, A. F., Sugiarti, \& Masri, M. (2016). Pengaruh Model Pembelajaran Blended Learning Terhadap Motivasi dan Hasil Belajar Siswa Kelas X SMA Negeri 1 Pitumpanua Kab . Wajo (Studi Pada Materi Pokok Sistem Periodik Unsur). Jurnal Chemica, 17(2), 8393.

Monica, M. (2013). Analysis of Perceptions of Conventional and ELearning Education in Corporate Training. Journal of Competitiveness, 5(4), 73-79.

Muchlis, E. E. (2012). Pengaruh Pendekatan Pendidikan Matematika Realistik Indonesia (PMRI) terhadap Perkembangan Kemampuan Pemecahan Masalah Siswa Kelas II SD Kartika 1.10 Padang. Jurnal Exacta, X(2), 136-139.

Muslim, S. R. (2015). Pengaruh Penggunaan Metode Student Facilitator and Explaining dalam 
Desimal, 2 (2), 2019 - 179

Fifit Novi Yanti , Farida , Iip Sugiharta

Pembelajaran Kooperatif terhadap Kemampuan Pemecahan Masalah Matematik Siswa SMK di Kota Tasikmalaya. Jurnal Penelitian Pendidikan dan Pengajaran Matematika, 1(1), 65-72.

Ningsih, Y. L., \& Jayanti. (2016). Hasil Belajar Mahasiswa Melalui Penerapan Model Blended Learning Pada Mata Kuliah Persamaan Diferensial. Jurnal Pendidikan Matematika Jpm Rafa, 2(1), 1-11.

Nortvig, A.-M. (2014). E-Learning In PolyTopic Settings. Electronic Journal of E-Learning, 12(2), 206-214.

Novitayati, R. (2013). Pengaruh Metode Blended Learning dan Self Regulated Learning terhadap Hasil Belajar Kognitif IPS. Jurnal Penelitian Kependidikan, 23(1), 4857.

Noviyana, H., \& Fitriani, D. (2018). Pengaruh Model Realistic Mathematics Education (RME) terhadap Kemampuan Pemecahan Masalah Matematis Siswa Kelas VIII SMP. In Seminar Nasional Matematika dan Pendidikan Matematika (pp. 385-392).

Rahmaningrum, V. N., \& Buditjahjanto, I. G. . A. (2016). Pengaruh Media Pembelajaran E-Learning Berbasis Edmodo pada Mata Pelajaran Penerapan Rangkaian Elektronika untuk Meningkatkan Hasil Belajar Siswa Kelas XI Teknik Audio Video di SMK Negeri 3 Surabaya. Jurnal Pendidikan Teknik Elektro, 5(3), 689-696.

Rizkiyah, A. (2015). Penerapan Blended Learning untuk Meningkatkan Hasil Belajar Siswa pada Mata Pelajaran Ilmu Bangunan di Kelas X TGB SMK Negeri 7 Surabaya. Jurnal Kajian
Pendidikan Teknik Bangunan, 1(1), 40-49.

Sari, A. R. (2013). Strategi Blended Learning untuk Peningkatan Kemandirian Belajar dan Kemampuan Critical Thinking Mahasiswa di Era Digital. Jurnal Pendidikan Akuntansi Indonesia, XI(2), 32-43.

Setiawan, R. H., \& Harta, I. (2014). Pengaruh Pendekatan Open-Ended dan Pendekatan Kontekstual terhadap Kemampuan Pemecahan Masalah dan Sikap Siswa terhadap Matematika. Jurnal Riset Pendidikan Matematika, 1(2), 240-256.

Sudibjo, A., \& Wasis. (2013). Penggunaan Media Pembelajaran Fisika dengan E-Learning Berbasis Edmodo Blog Education pada Materi Alat Optik untuk Meningkatkan Respons Motivasi dan Hasil Belajar Siswa di SMP Negeri 4 Surabaya. Jurnal Inovasi Pendidikan Fisika, 2(3), 187190.

Sudijono, A. (2008). Pengantar Statistik Pendidikan. Jakarta: Raja Grafindo Persada.

Sugiyono, S. (2017). Metode Penelitian Pendidikan Pendekatan Kuantitatif, Kualitataif dan R\&D. Bandung: Alfabeta.

Sutisna, A. (2016). Pengembangan Model Pembelajaran Blended Learning pada Pendidikan Kesetaraan Program Paket C dalam Meningkatkan Kemandirian Belajar. Jurnal Teknologi Pendidikan, 18(3).

Syaiful, S., Kusumah, Y. S., Sabandar, J., \& Dahrim, D. (2011). Peningkatan Kemampuan Pemecahan Masalah Matematis melalui Pendekatan Matematika Realistik. Jurnal 
Desimal, 2 (2), 2019 - 180

Fifit Novi Yanti , Farida , Iip Sugiharta

Pendidikan Matematikadan Sains Edisi 1.

Syarif, I. (2012). Pengaruh Model Blended Learning terhadap Motivasi dan Prestasi Belajar Siswa SMK. Jurnal Pendidikan Vokasi, 2(2), 234-249.

Syazali, M. (2015). Pengaruh Model Pembelajaran Creative Problem Solving Berbantuan Maple II terhadap Kemampuan Pemecahan Masalah Matematis. Al-Jabar: Jurnal Pendidikan Matematika, 6(1), 9198.

Tigowati, Efendi, A., \& Budiyanto, C. W. (2017). E-Learning Berbasis Schoology Dan Edmodo: Ditinjau dari Motivasi dan Hasil Belajar Siswa SMK. Elinvo (Electronics, Informatics, and Vocational Education), 2(1), 49-58.

Vernadakis, N., Giannousi, M., Derri, V., Michalopoulos, M., \& Kioumourtzoglou, E. (2012). The Impact of Blended and Traditional Instruction in Students'
Performance. Procedia Technology, 1, 439-443.

Wijaya, I., \& Arsyah, R. H. (2015). Pengaruh Pembelajaran E-Learning Berbasis Edmodo terhadap Hasil Belajar Simulasi Digital Kelas X SMK Negeri 9 Padang (Studi Kasus Jurusan Akomodasi Perhotelan ). Majalah Ilmiah UPI YPTK, 22(1), 2133.

Wulandari, P., Mujib, \& Putra, F. G. (2016). Pengaruh Model Pembelajaran Investigasi Kelompok Berbantuan Perangkat Lunak Maple terhadap Kemampuan Pemecahan Masalah Matematis. Al-Jabar: Jurnal Pendidikan Matematika, 7(1), 101107.

Yuhani, A., Zanthy, L. S., \& Hendriana, H. (2018). Pengaruh Pembelajaran Berbasis Masalah terhadap Kemampuan Pemecahan Masalah Matematis Siswa SMP. Jurnal Pembelajaran Matematika Inovatif, 1(3), 445-452. 